\title{
ANÁLISE DETALHADA DA ESTRUTURA E NORMAS DE UM PLANO DE CURSO
}

\author{
Natane Ribeiro de Carvalho ${ }^{1}$
}

\section{RESUMO}

Neste escrito será apresentado de forma resumida uma visão crítica e descritiva sobre o plano de curso e sua importância para o desenvolvimento do discente em um determinado curso, bem como a definição deste documento, sua estrutura e procedimentos que o norteia, destacando especialmente sobre ementa, conteúdo programático, habilidades, objetivos e procedimentos esperados no decorrer do curso e desenvolvimento do aluno. Além de discorrer sobre a metodologia e instrumentos de avaliação abordados neste processo.

Palavras-Chave: Plano de Curso. Criticidade. Ensino.

\section{ABSTRACT}

This writing will briefly present a critical and descriptive view of the course plan and its importance for the development of the student in a given course, as well as the definition of this document, its structure and procedures that guide it, with special emphasis on : syllabus, syllabus, skills, objectives and procedures expected during the course and student development. In addition to discussing the methodology and assessment tools covered in this process.

Keywords: Course Plan. Criticality. Teaching.

\section{RESUMEN}

En este escrito se presentará en un resumen una visión crítica y descriptiva sobre el plan del curso y su importancia para el desarrollo del alumno en un curso determinado, así como la definición de este documento, su estructura y procedimientos que lo guían, destacando especialmente sobre: menú, contenido programático, habilidades, objetivos y procedimientos esperados en el curso y desarrollo del alumno. Además de discutir la metodología y las herramientas de evaluación abordadas en este proceso.

Palabras clave: Plan de cursos. Criticidad. Enseñanza.

${ }^{1}$ Pedagoga, especialista em Arte e Educação. E-mail: profnatane@gmail.com 


\section{INTRODUÇÃO}

Podemos definir o Plano de Curso como um instrumento de trabalho, especialmente acadêmico que, tem como meta referenciar as técnicas, as metodologias, os conteúdos e procedimentos que serão explorados no processo de ensino-aprendizagem relacionados às unidades acadêmicas de um determinado curso, sejam eles da educação básica ou superior.

A elaboração do plano deve se dar em parceria com o corpo docente da unidade escolar, visando atender à característica interdisciplinar e contextualizada estabelecida pelos Parâmetros Curriculares Nacionais(PCNs). Por essa razão, a produção deste documento incita uma nova postura entre os profissionais do espaço de ensino, gerando debates que podem favorecer e promover ações norteadoras de um ensino mais coeso e coerente, norteando de maneira mais eficaz o ensino dos conteúdos programáticos.

Após sua produção, o plano de curso servirá para nortear os passos didáticos dos profissionais do seio escolar-acadêmico, no decorrer das atividades de ensino e aprendizagem de um determinado saber e área, organizando os conteúdos primordiais, os materiais e recursos a serem utilizados pelos docentes, os procedimentos e ações avaliativas, os eventos escolares etc.

Segundo Vasconcellos (2000), do ponto de vista educacional, o planejamento é um ato político-pedagógico, pois desvenda intenções. De acordo com este autor:

[...] planejar é elaborar o plano de intervenção na realidade, aliando às exigências de intencionalidade de colocação em ação, é um processo mental, de reflexão, de decisão, por sua vez, não uma reflexão qualquer, mas grávida de intenções na realidade (VASCONCELLOS, p.43, 2000).

Já Zanon e Althaus (2010) afirmam que o ato de planejar, organizar as ações docentes e discentes, exige o domínio de conhecimentos sobre os níveis que compõem o processo de planejamento.

Diante dessas visões, fica claro à relevância deste documento para a área educacional, as instituições prestadoras de serviços educacionais, estão 
cada dia mais rigorosas quanto à cobrança deste documento., pois tal qual afirma Libâneo (2013):

Os objetivos educacionais são uma exigência indispensável para o trabalho docente, requerendo um posicionamento ativo do professor em sua explicitação, seja no planejamento escolar, seja no desenvolvimento das aulas (LIBÂNEO, 2003).

\section{PASSOS E SEQÜÊNCIA PARA ELABORAR UM PLANO DE CURSO}

O $1^{\circ}$ passo a ser dado neste sentido será o de escolher uma determinada instituição de ensino, analisar de forma crítica sua identidade, necessidades, valores e foco, logo, dar início ao processo de levantar informações sobre o objeto de estudo. Um exemplo de instituição escolhida para este fim será a IES (Instituição de Ensino Superior) Mackenzie.

O $2^{\circ}$ passo será o de escolher um plano de um determinado curso para assim, dar início a análise de sua estrutura. Neste caso, foi escolhido o referido plano do curso de Design, da IES Mackenzie, no qual são apresentados os elementos de acordo com as orientações normativas deste tipo de documento escolar.

\section{ANÁLISE DO PLANO DE CURSO}

A ementa do curso da Faculdade de Arquitetura e Urbanismo do Curso de DESIGN visa apresentar ao estudante a reflexão sobre o papel do design na contemporaneidade.

Estuda das metodologias operacionais de projeto, com ênfase nas cartesianas e nas de caráter artístico, desenvolvimento as habilidades básicas para o exercício de projeto: técnicas de observação, raciocínio visual, diagnóstico e proposição, representação e expressão formal.

Análise de projetos conduzindo à criação de repertório crítico. Vivência do processo de projeto: planejamento, problematização, pesquisa, 
conceituação, experimentação, configuração, meios de produção, avaliação, documentação e apresentação.

O conteúdo programático pauta-se em eixos temáticos analisados, tal como "O Homem e a Contemporaneidade" que orienta a componente curricular de Projeto I que, por sua vez, faz convergir as atividades dos demais componentes alocados na $1^{\text {a }}$ etapa.

Os temas, assuntos e conceitos a serem abordados contemplarão a dimensão teórica e prática da atividade projetual e alimentarão as quatro atividades que compõem este componente curricular: Metodologia operacional de projeto, Prática Projetual, Meios de expressão e Meios de produção.

O plano almeja levar os estudantes a conhecerem os variados escopos da atividade do designer na contemporaneidade com o intuito de ser capaz de olhar para situações de vida e identificar problemas passíveis de serem mitigados por proposições de Design. A elaborarem soluções criativas para os problemas identificados.

A construírem protótipos, testar sua eficácia, analisar os resultados com vistas a uma experiência de aprendizado significativo. E a vivenciarem situações de projeto de modo a tornar consciente a necessidade de uma atitude proativa e investigativa teórico-prática e apropriar-se da maneira de pensar e agir do designer.

Quanto às técnicas, recursos e metodologia ensino abordada neste curso, é possível afirmar que os discentes são estimulados as mais diversas práticas, não restritas necessariamente apenas à sala e horário de aula, exigindo do aluno postura proativa de modo a exercer plenamente o protagonismo estudantil em um ambiente de cooperação onde o trabalho em grupo será incentivado intercalando momentos de estudo individual.

Análises de Projetos de Referência, Estudos de Caso, Pesquisas teórica e de campo serão alimentadas por recursos didáticos indicados pelo professor e seus resultados apresentados em seminários que serão matéria para identificação de problemas dentro do tema a ser proposto. As aulas possuem duração de 5 horas diárias, divididas nos 5 dias da semana.

Sobre os métodos de ensino, Araújo (2008) afirma que: 
Ela [a aula] é feita de prévias e planejadas escolhas de caminhos, que são diversos do ponto de vista dos métodos e técnicas de ensino; [...] também se constrói, em sua operacionalização, por percalços, que implicam correções de rota na ordem didática, bem como mudanças de rumo; [...] está sujeita a improvisos, porque não foram previstos, mas não pode constituir-se por improvisações. (ARAUJO, p.60-62, 2008).

Em se tratando de avaliação, essas ocorrem de forma contínua e processual e alinhando-se à metodologia ativa adotada no componente curricular. Como instrumento de diagnóstico e correção de rotas seu foco está não somente na qualidade final do trabalho como também na atuação do aluno diante de seu próprio percurso de aprendizagem. As três avaliações propostas estão alocadas em momentos estratégicos da atividade projetual.

$\mathrm{A} 1^{\circ}$ refere-se à problematização e será realizada na forma de apresentação em sala de aula para o grupo. A $2^{\circ}$ avaliação consubstancia a fase de criação e a última diz respeito à finalização do projeto com a apresentação para professores convidados e posterior entrega do Caderno completo de Projeto.

Todas as notas serão de 0 a 10 com peso igual a 1 . Parte das duas primeiras notas serão atribuídas pelo professor de projeto sendo que, $30 \%$ da primeira nota é relativa à uma avaliação realizada por outros alunos membros de seus grupos de trabalho com o auxílio de ferramenta a ser explicada em sala de aula e $50 \%$ da segunda nota é relativo à autoavaliação do aluno com o intuito de promover uma reflexão de suas atitudes e desempenho até aquele momento.

A nota da $3^{a}$ avaliação será composta, além das notas do professor de projeto, pelas de outros professores envolvidos na etapa, bem como demais que estejam capacitados a avaliar o projeto apresentado. Não alcançada a média mínima de 7,5 o discente apresentará o projeto revisado, de acordo com orientação de seu professor de Projeto, e será considerado aprovado se obtiver a média final igual ou superior a 6,0.

Sobre a relação entre a avaliação e o planejamento, Gandin (1994) relata que: 
[...] o processo de planejamento inclui o processo de avaliação, sem exagero pode-se afirmar que o planejamento é um processo de avaliação que se junta a ação para mudar o que não esteja de acordo com o ideal (GANDIN, 1994).

\section{CRÍTICA ACERCA DOS ASPECTOS MAIS RELEVANTES DO PLANO E OS PONTOS FRACOS}

Foi possível notar que o plano de curso apresentado segue de forma coesa e coerente os preceitos que regem o curso, por isso, levou em conta vários aspectos, no intuito de garantir o aprendizado do discente. Contudo, pareceu que "poderia" haver um aporte informando ao aluno, que ajustes poderiam ser realizados no decorrer deste percurso, uma vez que o planejamento é uma prévia do que se almeja alcançar e, que no caminhar deste processo, tanto professores como alunos poderiam saltar etapas já conhecidas por eles, complementar, retroagir algum tópico ou assunto que pudesse enriquecer ainda mais o processo de formação e aquisição de conhecimento dos envolvidos.

Como um aspecto relevante no planejamento em si, percebeu-se que este não se restringe ao programa de conteúdo a ser ministrado em cada disciplina. Ele vai muito além. Está inserido dentro do plano global da instituição, que inclui o papel social, as metas e seus objetivos. A IES, por sua vez, faz parte do sistema educacional e é ligada às secretarias de Educação nos diversos níveis, que também determinam expectativas de aprendizagem para as diferentes áreas de conhecimento.

\section{CONSIDERAÇÕES FINAIS}

Tal qual estudamos, o plano de curso é imprescindível em todas as áreas do conhecimento, pois ele favorece uma visão cristalina e ampla dos conhecimentos a serem transmitidos aos discentes, facilitando a exploração das estratégias que podem impactá-los e assegurar que os conhecimentos/conteúdos sejam absorvidos e úteis à vida dos estudantes. 
Viu-se que este documento precisa ser flexível, pois poderá sofrer ajustes ou alterações no decorrer do ano e processo letivo, além de abarcar os seguintes tópicos: conexão e sequencialidade dos conteúdos didáticos; apresentação da proposta pedagógica; descrição dos materiais que serão utilizados; os tipos, os meios, as formas e métodos avaliativos, os objetivos gerais e específicos e finalmente a conclusão.

\section{REFERÊNCIAS BIBLIOGRÁFICAS}

ARAUJO, J.C.S. Disposição da aula: os sujeitos entre a técnica e a polis. In: VEIGA, I. P.A. (Org.) Aula: gênese, dimensões, princípios e práticas. Campinas: Papirus, 2008.

GANDIN, D. A prática do planejamento participativo. Petrópolis: Vozes, 1994.

LIBÂNEO, J.C. Didática. 2ª ed. São Paulo: Cortez, 2013.

VASCONCELLOS, C. S. Planejamento: projeto de ensino-aprendizagem e projeto político pedagógico. 9 ed. São Paulo: Libertad, 2000.

ZANON, D. P.; ATHAUS, M.T.M. Didáticall. Ponta Grossa: UEPG/NUEAD, $2010 \quad$ Disponível em: https://www.mackenzie.br/fileadmin/user_upload/10_ETAPA.pdf. Acesso: 17/06/2021 